\title{
Association of vitamin $D$ status and thyroid function among type 2 diabetic mellitus patients
}

\begin{abstract}
Introduction: Vitamin D deficiency (VDD) has been identified as a risk factor for diabetes mellitus and autoimmune diseases. Positive correlations between VDD and thyroid dysfunction among type 2 diabetes mellitus (T2DM) patients have been reported by several authors Therefore, in the present study, we examined the relationship between thyroid stimulating hormone (TSH) and vitamin D status among patients with T2DM.
\end{abstract}

Method: A cross-sectional single centre study was conducted in 4053 patients with T2DM. Patients with T2DM attended the Diabetes Centre at King Fahad Armed Forces Hospital, Jeddah, Saudi Arabia between January 2018 and December 2018 were recruited. The serum concentration of 25-OHD, TSH, and $\mathrm{HbA} 1 \mathrm{c}$ were measured.

Results: A total of 2019 participants were included in this study. Average age of the study population was $51.3 \pm 16.4$ years. Expectedly, $47.5 \%$ had VDD. In $123(6.1 \%)$ of the cases, TSH was lower than $0.22 \mathrm{mIU} / \mathrm{L}$ and in $1538(74.0 \%)$, TSH was within normal reference range. Abnormally high levels of TSH $(>4.2 \mathrm{mIU} / \mathrm{L})$ were reported in $401(19.9 \%)$ subjects. Serum $25-O H D$ level was significantly different among the study subgroups $(\mathrm{P}<0.0001)$. In post hoc analysis, it was determined that subjects with TSH levels $<0.22 \mathrm{mIU} / \mathrm{L}$ had significantly higher 25 -OHD concentrations $(69.2 \pm 37.8$ $\mathrm{nmol} / \mathrm{L})$ compared to subjects with normal TSH levels $(58.0 \pm 31.3 \mathrm{nmol} / \mathrm{L} ; \mathrm{P}<0.0001)$ and those with elevated TSH concentrations $(55.3 \pm 31.3 \mathrm{nmol} / \mathrm{L} ; \mathrm{P}<0.0001)$. However the difference in serum 25-OHD concentrations was not significant between subject with normal and those with elevated TSH levels $(\mathrm{P}=0.3)$.

In order to identify the independent factors affecting 25-OHD levels, a multivariate linear regression model was constructed using the serum 25-OHD concentrations as the dependent factor. Age, gender, $\mathrm{HbA} 1 \mathrm{c}$ and TSH were the independent predictors of $25-\mathrm{OHD}$ levels. The second linear regression analysis using serum TSH concentrations as the dependent variable was performed with Age, gender, HbAlc and 25-OHD levels as independent variables. In the constructed model, age, gender and $\mathrm{HbA} 1 \mathrm{c}$ and 25 OHD were found not to be independent predictors of serum TSH level.

Conclusion: This study suggests a positive associations between the VDD and TSH level among T2DM patients. Age, gender, HbA1c and TSH level were identified as the independent predictors of 25-OHD level.

Keywords: type 2 diabetes mellitus, thyroid function and vitamin D deficiency
Volume 9 Issue $3-2019$

\author{
Khalid S Aljabri \\ Department of Endocrinology, King Fahad Armed Forces \\ Hospital, Kingdom of Saudi Arabia
}

Correspondence: Khalid S Aljabri, Department of Endocrinology, King Fahad Armed Forces Hospital, Jeddah, PO Box 9862. Jeddah 21159, Kingdom of Saudi Arabia, Email khalidsaljabri@yahoo.com

Received: April 17, 2019| Published: May 24, 2019

\section{Introduction}

Vitamin D is an important element for skeletal health and it may also affect extra-skeletal health such as association with autoimmune diseases. ${ }^{1-5}$ Inclusive studies in have reported an association between thyroid autoimmunity and 25-hydroxyvitamin D (25-OHD) ${ }^{6-8}$ Type 2 diabetes mellitus (T2DM) prevalence in Saudi Arabia is high, reaching up to $30 \% .{ }^{9}$ Vitamin D deficiency (VDD) remains a major health problem. ${ }^{10}$ VDD has received special attention lately because of its high incidence and its implication in the genesis of multiple chronic illnesses. The high prevalence of VDD in general population underlines the fact that VDD is more common in chronic diseases like diabetes mellitus.

T2DM and hypothyroidism are the main threats in developed and developing countries. ${ }^{11,12}$ T2DM increases the risk of thyroid dysfunction in the long-term. ${ }^{13-19}$ T2DM and hypothyroidism are the primary reasons for mortality and morbidity in most high income and developing countries. ${ }^{15-19}$ However, several studies have shown a higher prevalence of hypothyroidism occurring among T2DM patients. ${ }^{17-22}$ Moreover, positive correlations between VDD and hypothyroidism among T2DM patients have been reported. ${ }^{1,7,21-23}$ 25-OHD was shown to affect the thyroid gland through immunemediated processes by directly inhibiting thyrotropin-stimulated iodide uptake..$^{24}$ Moreover, high 25-OHD status is associated with low thyroid-stimulating hormone (TSH) ${ }^{25}$ Therefore, in the present study, we examined the relationship between serum TSH levels and vitamin D status among patients with T2DM.

\section{Methods}

A cross-sectional single centre study was conducted in 2019 patients with T2DM attended the Diabetes Centre at King Fahad Armed Forces Hospital, Jeddah, Saudi Arabia between January 
2018 and December 2018. Eligible patients were 20 years or older. Exclusion criteria were known hepatic or renal disease, metabolic bone disease, malabsorption, hypercortisolism, pregnancy and medications influencing bone metabolism. The serum concentration of 25-OHD was measured by competitive protein binding assay using kits (Immunodiagnostic, Bensheim, Germany). VDD was defined as serum 25-OHD concentration $<50 \mathrm{nmol} / \mathrm{L} .{ }^{1}$ Glycosylated hemoglobin $(\mathrm{HbAlc})$ was measured by the high performance liquid chromatography method (Bio-Rad Laboratories, Waters, MA, USA). TSH levels between 0.22-4.2 mIU/L were regarded normal. ${ }^{26}$ Participants were divided to three subgroups according to their TSH level (below $<0.22 \mathrm{mIU} / \mathrm{L}, 0.22-4.2 \mathrm{mIU} / \mathrm{L}$ and $>4.2 \mathrm{mIU} / \mathrm{L}$ ). ${ }^{27}$ The study was approved by the ethical committee board of King Fahad Armed Forces Hospital.

\section{Statistical analysis}

Data are presented as means \pm standard deviation (SD) or numbers (\%). Quantitative variables were compared between two groups by using the Student's test. Differences in categorical variables were analysed using the chi-square test. Differences in mean serum 25 OHD levels were tested with ANOVA. The relationship between continuous variables was assessed using coefficients of correlation. Linear regression analyses were performed to examine the factors that predicted serum concentrations of 25(OH)D. Multivariate linear regression model was constructed using serum $25(\mathrm{OH}) \mathrm{D}$ and serum TSH as the dependent variables and factors with either a P-value less than 0.15 in the univariate analysis or a previously reported association with either 25-OHD or TSH as independent variables. Logistic regression analysis was carried out to estimate odds ratio
(OR) and $95 \%$ CI. P value $<0.05$ indicates significance. The statistical analysis was conducted with SPSS version 23.0 for Windows.

\section{Results}

A total of 2019 participants were included in this study. Average age of the study population was $51.3 \pm 16.4$ years (Table 1). Expectedly, $47.5 \%$ had VDD. In $123(6.1 \%)$ of the cases, TSH was lower than 0.22 $\mathrm{mIU} / \mathrm{L}$ and in 1538 (74.0\%), TSH was within normal reference range. Abnormally high levels of TSH $(>4.2 \mathrm{mIU} / \mathrm{L})$ were reported in 401 $(19.9 \%)$ subjects. Table 1 summarizes the characteristics of the three subgroups of study population according to their serum TSH level. Serum 25-OHD level was significantly different among the study subgroups $(\mathrm{P}<0.0001)$. In post hoc analysis, it was determined that subjects with TSH levels $<0.22 \mathrm{mIU} / \mathrm{L}$ had significantly higher 25 OHD concentrations $(69.2 \pm 37.8 \mathrm{nmol} / \mathrm{L})$ compared to subjects with normal TSH levels $(58.0 \pm 31.3 \mathrm{nmol} / \mathrm{L} ; \mathrm{P}<0.0001)$ and those with elevated TSH concentrations $(55.3 \pm 31.3 \mathrm{nmol} / \mathrm{L} ; \mathrm{P}<0.0001)$. However the difference in serum 25-OHD concentrations was not significant between subject with normal and those with elevated TSH levels ( $\mathrm{P}$ $=0.3$ ). In order to identify the independent factors affecting 25-OHD levels, a multivariate linear regression model was constructed using the serum 25-OHD concentrations as the dependent factor (Table 2). Age, gender, $\mathrm{HbAlc}$ and TSH were the independent predictors of 25OHD levels. The second linear regression analysis using serum TSH concentrations as the dependent variable was performed with Age, gender, $\mathrm{HbAlc}$ and 25-OHD levels as independent variables. In the constructed model, age, gender and $\mathrm{HbAlc}$ and 25-OHD were found not to be independent predictors of serum TSH level (Table 3).

Table I Distribution of patients based on TSH categories of suppressed TSH, normal TSH and elevated TSH [mean \pm standard deviation or number (\%)]

\begin{tabular}{|c|c|c|c|c|c|c|}
\hline \multirow{2}{*}{\multicolumn{2}{|c|}{ Variable }} & \multicolumn{3}{|c|}{ Thyroid Stimulating Hormone (m/U/l) } & \multirow[t]{2}{*}{ Total } & \multirow[t]{2}{*}{$P$ values } \\
\hline & & $<0.22$ & $0.22-4.2$ & $>4.2$ & & \\
\hline \multicolumn{2}{|c|}{ Numbers } & $123(6.1)$ & $1538(74.0)$ & $401(19.9)$ & 2019 & \\
\hline \multicolumn{2}{|c|}{ Age (years) } & $50.5 \pm 13.7$ & $51.5 \pm 16.4$ & $50.7 \pm 17.4$ & $51.3 \pm 16.4$ & 0.6 \\
\hline \multirow[t]{2}{*}{ Gender } & Male & $12(9.8)$ & $382(25.6)$ & $87(21.7)$ & $48 I(23.8)$ & $<0.0001$ \\
\hline & Female & III (90.2) & $1113(74.4)$ & $314(78.3)$ & $1538(76.2)$ & \\
\hline \multicolumn{2}{|c|}{$\mathrm{HbAlc}(\%)$} & $6.8 \pm 1.8$ & $7.5 \pm 2.0$ & $7.8 \pm 2.1$ & $7.5 \pm 2.0$ & 0.004 \\
\hline \multicolumn{2}{|c|}{ 25-hydroxyvitamin $\mathrm{D}$ (nmol/L) } & $69.2 \pm 37.8$ & $58.0 \pm 31.3$ & $55.3 \pm 31.3$ & $58.1 \pm 31.7$ & $<0.0001$ \\
\hline \multicolumn{2}{|c|}{ Vitamin D deficiency } & $37(30.1)$ & $710(47.5)$ & $212(52.9)$ & $959(47.5)$ & $<0.0001$ \\
\hline \multicolumn{2}{|c|}{ TSH (mlU/l) } & $0.1 \pm 0.06$ & $2.0 \pm 1.0$ & $10.3 \pm 18.3$ & $3.5 \pm 8.9$ & $<0.0001$ \\
\hline \multicolumn{2}{|c|}{ FT4 (pmol/l) } & $17.2 \pm 5.4$ & $13.7 \pm 4.4$ & $13.3 \pm 3.2$ & $13.8 \pm 4.3$ & $<0.0001$ \\
\hline
\end{tabular}

Table 2 Linear regression analysis using serum 25-hydroxyvitamin D concentrations as the dependent variable

\begin{tabular}{lllll}
\hline Parameters & Coefficients & Std. Error & $\mathbf{9 5 \%}$ Confidence interval & P value \\
\hline Gender & 5.078 & 1.996 & $1.162-8.994$ & 0.01 \\
Age (years) & 0.427 & 0.057 & $0.316-0.538$ & $<0.000 \mathrm{I}$ \\
HbAlc (\%) & -1.978 & 0.452 & -1.773 & $<0.000 \mathrm{I}$ \\
TSH & 0.333 & 0.161 & $0.018-0.648$ & 0.04 \\
FT4 & 2.258 & 0.307 & $1.656-2.860$ & $<0.000 \mathrm{I}$ \\
\hline
\end{tabular}


Table 3 Linear regression analysis using serum concentrations of thyroid stimulating hormone as the dependent variable

\begin{tabular}{lllll}
\hline Parameters & Coefficients & Std. Error & $\begin{array}{l}\text { 95\% Confidence } \\
\text { interval }\end{array}$ & $\begin{array}{l}\text { P } \\
\text { value }\end{array}$ \\
\hline Gender & -0.307 & 0.328 & -1.287 & 0.3 \\
Age (years) & 0 & 0.01 & -0.038 & 0.9 \\
HbAlc (\%) & 0.054 & 0.076 & -0.309 & 0.5 \\
25 -hydroxyvitamin D (nmol/l) & 0.004 & 0.005 & -0.02 & 0.4 \\
\hline
\end{tabular}

\section{Discussion}

Diabetes mellitus is a worldwide epidemic and currently the most prevalent chronic illness in the world having a prevalence of around $9 \%$ in the adult population and $30 \%$ of Saudi adults. ${ }^{9,28}$ Moreover, VDD has received special attention lately because of its high incidence and its implication in the genesis of multiple chronic illnesses. VDD and T2DM are usually recognized as a complication and risk for thyroid disease. ${ }^{29} \mathrm{We}$ found VDD to be common (47.5\%). In addition, high levels of TSH have been associated with lower 25-OHD levels. Moreover, suppressed levels of TSH have been associated with higher 25-OHD levels. In addition, a linear association between TSH and 25OHD has been noticed among T2DM patients. Though higher levels of 25-OHD with suppressed TSH levels might be due to an increased absorption of 25-OHD in hyperthyroid state. Metabolism of 25-OHD is also reciprocally regulated by thyroid hormones. Histological examination of the skin in hypothyroid patients has shown epidermal thinning and hyperkeratosis. ${ }^{30,31}$ Finally, the body may not activate vitamin D properly. ${ }^{32,33}$

We identified age, gender, HbAlc and TSH as the independent predictors of 25-OHD level. Thyroid disorders are more common in females by $5-10$ times. $^{29,34,35}$ It has been shown that serum levels of 25-OHD decrease with age. ${ }^{36}$ Moreover, we found age has shown a positive correlation with $25-\mathrm{OHD}$ level. As the study population grow older, 25-OHD concentrations increase. We hypothesize that such finding due to the fact our subjects in the sixth decade of their lives (mean $50.5 \pm 13.7$ years old). Higher levels of 25-OHD have been reported in older patients compared to younger counterparts. ${ }^{37,38}$ This could be due to the higher consumption of Vitamin D supplements in this age group.

VDD has received special attention lately because of its high incidence and its implication in the genesis of multiple chronic illnesses. The high prevalence of VDD in our study population underlines the fact that VDD is more common in chronic diseases like diabetes mellitus. Our study showed that 25-OHD was inadequate in a half of our population of patients with T2DM. Lower 25-OHD levels were associated with a poor glycemic control. These findings are supported by a number of international studies. Some studies showed no association of a low 25-OHD levels with HbA1c levels. ${ }^{39}$ But inverse correlation between the level of 25-OHD and HbAlc is well known. ${ }^{40,41}$ In many studies 25-OHD levels were low in subjects having higher $\mathrm{HbAlc}$ values in patients with T2DM indicating that they are inversely related. ${ }^{42-44}$ We had some limitations. study was done at only one centre and was done at one point of time. The study sample confined to patients with T2DM but without comparable groups.

\section{Conclusion}

This study suggests positive associations between the VDD and TSH level among T2DM patients. Age, gender, HbA1c and TSH level were identified as the independent predictors of 25-OHD level.

\section{Acknowledgments}

There is no any financial support or relationships that may pose conflict of interest

\section{Conflicts of interest}

Author declares that there is no conflict of interest.

\section{References}

1. Holick MF. Vitamin D deficiency. N Engl J Med. 2007;357(3):266-281.

2. Vanoirbeek E, Krishnan A, Eelen G, et al. The anti-cancer and antiinflammatory actions of 1,25(OH)2D3. Best Pract Res Clin Endocrinol Metab. 2011;25:593-604.

3. Woloszynska-Read A, Johnson CS, Trump DL. Vitamin D and cancer: clinical aspects. Best Pract Res Clin Endocrinol Metab. 2011;25(4):605615 .

4. Leu M, Giovannucci E. Vitamin D: epidemiology of cardiovascular risks and events. Best Practice \& Research Clinical Endocrinology \& Metabolism. 2011;25:633-646.

5. Van Belle TL, Gysemans C, Mathieu C. Vitamin D in autoimmune, infectious and allergic diseases: a vital player? Best Pract Res Clin Endocrinol Metab. 2011;25(4):617-632.

6. Goswami R, Marwaha RK, Gupta N, et al. Prevalence of vitamin D deficiency and its relationship with thyroid autoimmunity in Asian Indians: a community-based survey. Br J Nutr. 2009;102(3):382-386.

7. Kivity S, Agmon-Levin N, Zisappl M, et al. Vitamin D and autoimmune thyroid diseases. Cell Mol Immunes. 2011;8(3):43-247.

8. Tamer G, Arik S, Tamer I, et al. Relative vitamin D insufficiency in Hashimoto's thyroiditis. Thyroid. 2011;21(8):891-896.

9. Alqurashi KA, Aljabri KS, Bokhari SA. Prevalence of diabetes mellitus in a Saudi community. Ann Saudi Med. 2011;31(1):19-23.

10. Holick MF. High prevalence of vitamin D inadequacy and implications for health. Mayo Clin Proc. 2006;81(3):353-373.

11. Alberti KG, Eckel RH, Grundy SM, et al. Harmonizing the metabolic syndrome: a joint interim statement of the International Diabetes Federation Task Force on Epidemiology and Prevention; National Heart, Lung, and Blood Institute; American Heart Association; World Heart Federation; International Atherosclerosis Society; and International Association for the Study of Obesity. Circulation. 2009;120(16):1640-1645. 
12. Bener A, Zirie M, Musallam M, et al. Prevalence of metabolic syndrome according to Adult Treatment Panel III and International Diabetes Federation criteria: a population-based study. Metab Syndr Relat Disord. 2009; 7(3):221-229.

13. Bener A, Al-Hamaq AO, Kurtulus EM, et al. The role of vitamin D, obesity and physical exercise in regulation of glycemia in Type 2 Diabetes Mellitus patients. Diabetes Metab Syndr. 2016;10(4):198-204.

14. Al-Wazzan HT, Daban AH, Askar RA. et al. Prevalence and associated factors of thyroid dysfunction among type 2 diabetic patients in Kuwait. Alex Bull. 2010;46(2):141-148.

15. Papazafiropoulou A, Sotiropoulos A, Kokolaki A, et al. Prevalence of thyroid dysfunction among greek type 2 diabetic patients attending an outpatient clinic. J Clin Med Res. 2010;2(2):75-78.

16. Akbar DH, Ahmed MM, Al-Mughales J. Thyroid dysfunction and thyroid autoimmunity in Saudi type 2 diabetics. Acta Diabetol. 2006;43(1):14-18.

17. Bener A, Ozdenkaya Y, Barişik CC, et al. The impact of metabolic syndrome on increased risk of thyroid nodules and size. Health Service Res Man Epidemiology. 2018;5:1-6.

18. Sarfo-Kantanka O, Sarfo FS, Ansah EO, et al. Frequency and determinants of thyroid autoimmunity in Ghanaian type 2 diabetes patients: a casecontrol study. BMC Endocr Disord. 2017;17(1):2.

19. Centeno Maxzud M, Gomez Rasjido L, Fregenal M, et al. Prevalence of thyroid dysfunction in patients with type 2 diabetes mellitus. Medicina ( $B$ Aires). 2016;76(6):355-358

20. Van Belle TL, Gysemans C, Mathieu C. Vitamin D and diabetes: the odd couple. Trends Endocrinol Metab. 2013;24(11):561-568.

21. Bozkurt NC, Karbek B, Ucan B, et al. The association between severity of vitamin D deficiency and Hashimoto's thyroiditis. Endocr Pract. 2013;19(3):479-484.

22. Kim D. Low vitamin D status is associated with hypothyroid Hashimoto's thyroiditis. Hormones (Athens). 2016;15(3):385-393.

23. Mazokopakis EE, Kotsiris DA. Hashimoto's autoimmune thyroiditis and vitamin D deficiency, Current aspects. Hell J Nucl Med. 2014;17(1):37-40.

24. Berg JP, Liane KM, Bjorhovde SB, et al. VitaminDreceptor binding and biological effects of cholecalciferol analogues in rat thyroid cells. Journal of Steroid Biochemistry and Molecular Biology. 1994;50(3-4):145-150.

25. Chailurkit LO, Aekplakorn W, Ongphiphadhanakul B. High vitamin D status in younger individuals is associate dwith low circulating thyrotropin Thyroid. 2013;23(1):25-30.

26. Jun JE, Jee JH, Bae JC, et al. Association between changes in thyroid hormones and incident type 2 diabetes: A seven-year longitudinal study. Thyroid. 2016;27(1):11.

27. Ginde AA, Liu MC, Camargo CA. Demographic differences and trends of vitamin d insufficiency in the us population, 1988-2004. Arch Intern Med. 2009;169(6):626-632.
28. World Health Organization. Global status report on non-communicable diseases. 2014.

29. Matyjaszek-Matuszek B, Pyzik A, Nowakowski A, et al. Diagnostic methods of tsh in thyroid screening tests. Ann Agric Environ Med. 2013;20(4):731-735

30. Bikle DD. Vitamin d metabolism and function in the skin. Mol Cell Endocrinol. 2011;347(1-2):80-89.

31. Safer JD. Thyroid hormone action on skin. Dermatoendocrinol. 2011;3(3):211-215.

32. Hanley K, Jiang Y, Katagiri C, et al. Epidermal steroid sulfatase and cholesterol sulfotransferase are regulated during late gestation in the fetal rat. J Invest Dermatl.l 1997;108(6):871-875.

33. Theodore C, Friedman. Vitamin D Deficiency and Thyroid Disease.

34. Faggiano A, Del Prete M, Marciello F, et al. Thyroid diseases in elderly Minerva Endocrinol. 2011;36(3):211-131.

35. Mackawy AM, Al-ayed BM, Al-rashidi BM. Vitamin D Deficiency and Its Association with Thyroid Disease. Int $J$ Health Sci (Qassim). 2013;7(3):267-275.

36. Mitra N, Leili P, Saina A, et al. Association of Vitamin D Deficiency and Thyroid Function in Postmenopausal Women. Advanced Pharmaceutical Bulleti. 2016;6(4):639-644.

37. Hashemipour S, Larijani B, Adibi H, et al. Vitamin d deficiency and causative factors in the population of tehran. BMC Public Health. 2004;4:38.

38. Asadi M, Jouyandeh Z, Nayebzadeh F, et al. Does aging increase vitamin d serum level in healthy postmenopausal women? Acta Med Iran 2013;51(10):701-704.

39. Bashir F, Khan ZU, Qureshi S, et al. Prevalence of Hypovitaminosis D in Type 2 Diabetes Mellitus and its Relationship with Glycemic Control. J Liaquat Uni Med Health Sci. 2016;15(02):83-89.

40. Husemoen LLN, Thuesen BH, Fenger M, et al. Serum $25(\mathrm{OH}) \mathrm{D}$ and Type 2 Diabetes Association in a General Population: A prospective study. Diabetes Care. 2012; 35(8):1695-1700.

41. Palomer X, Gonzalez-Clemente J, Blanco-Vaca F, et al. Role of vitamin $\mathrm{D}$ in the pathogenesis of type 2 diabetes mellitus. Diabetes Obes Metab. 2008;10(3):185-197.

42. Hutchinson MS, Figenshau Y, NjølstadI, et al. Serum25-hydroxyvitamin D levels are inversely associated with glycatedhaemoglobin $(\mathrm{HbA}(1 \mathrm{c}))$. The TromsøStudy. Scand J Clin Lab Invest. 2011;71(5):399-406.

43. Kositsawat J, Freeman VL, Gerber BS, et al. Association of A1Clevels with vitamin D status in U.S. adults: data from the National Health andNutrition Examination Survey.. Diabetes Care.2010;33(6):1236-1238.

44. Tahrani AA, Ball A, Shepherd L, et al. The prevalence of vitamin D abnormalities in South Asians with type 2 diabetes mellitus in the UK. Int J Clin Pract. 2010;64(3):351-355. 